\title{
O OLHAR DAS COMUNIDADES DE SANTO AMARO DO MARANHÃO FRENTE AO PROJETO DE LEI DO SENADO N 465, DE 2018
}

\section{The view of the communities of Santo Amaro do Maranhão in front of the senate Law Project $n^{\circ} 465,2018$}

Itaan de Jesus Pastor Santos Universidade Estadual do Maranhão(UEMA)

Michelle Santos Rocha Universidade Estadual do Maranhão (UEMA)

Informações do artigo

Recebido em 22/08/2020

Aceito em 14/12/2020

doi>: https://doi.org/10.25247/2447-861X.2020.n251.p603-618

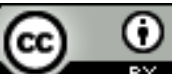

Esta obra está licenciada com uma Licença Creative Commons Atribuição 4.0 Internacional.

\section{Como ser citado (modelo ABNT)}

SANTOS, Itaan de Jesus Pastor; ROCHA, Michelle Santos. O olhar das comunidades de Santo Amaro do Maranhão frente ao Projeto de Lei do Senado $n^{\circ} 465$, de 2018. Cadernos do CEAS: Revista Crítica de

Humanidades. Salvador/Recife, v. 45, n. 251, p. 603618, set./dez., 2020. DOI: https://doi.org/10.25247/2447$\underline{861 X .2020 . n 251 . p 603-618}$

\begin{abstract}
Resumo
Geralmente, grandes projetos propõem desenvolvimento para as comunidades afetadas. Refere-se a um assunto desafiador para todos os atores envolvidos no território, tanto na sua diversidade como complexidade. O Projeto de Lei do Senado (PLS) 465/2018 planeja alterar os limites do Parque Nacional dos Lençóis Maranhenses, ampliando e excluindo áreas para promover o desenvolvimento do turismo na região e fazer justiça com as comunidades que precisam de equipamentos públicos básicos. Segundo a equipe multidisciplinar de pesquisadores do Grupo de Estudos Rurais e Urbanos (GERUR), da Universidade Federal do Maranhão, que realizou um Relatório Técnico deste PLS, em fevereiro de 2019, considerou que "entre outros efeitos danosos, caso o PLS prospere, será o de possibilitar que terras públicas de unidades de conservação de proteção integral, entrem para o mercado e passem às mãos de particulares". O objetivo deste artigo é explicar qual o panorama das comunidades envolvidas neste projeto alicerçado na problemática de como realmente é a percepção destes atores frente a esta questão. Para isso, estudos foram realizados através de pesquisas bibliográficas e relatórios técnicos, análises de audiências e entrevistas com famílias de algumas comunidades de Santo Amaro que adentram neste propósito. Conclui-se que através do diálogo com as comunidades poderá trazer um novo olhar quando o assunto se trata de desenvolvimento em comunidades.

Palavras-Chave: PSL 465/2018. Desenvolvimento. Comunidades.

Abstract

Generally, large projects propose development for the affected communities. It refers to a challenging issue for all actors involved in the territory, both in its diversity and complexity. The senate law project (PLS) 465/2018 plans to change the boundaries of the Lençóis Maranhenses National Park expanding and excluding areas to promote tourism development in the region and to do justice to communities that need basic public facilities. According to the multidisciplinary team of researchers from the Rural and Urban Studies Group (GERUR), of the Federal University of Maranhão, which carried out a Technical Report of this PLS in February 2019, considered that "Among other damaging effects, if the PLS prosper, it will be to enable public lands of protected areas of integral protection to enter the market and pass into the hands of private individuals". The purpose of this article is to explain the panorama of the communities involved in this project based on the problem of how these actors really perceive this issue. To this end, studies were carried out through bibliographic searches and technical reports, analysis of audiences and interviews with families from some communities in Santo Amaro who entered into this purpose, It is concluded that through the dialogue with the communities it can bring a new look when the subject is about development in communities.

Keywords: PSL 465/2018. Development. Communities.
\end{abstract}

\section{Introdução}

O Parque Nacional dos Lençóis Maranhenses (PNLM) é constituído pelos municípios de Barreirinhas (44,9\% da área do Parque), Santo Amaro do Maranhão (42,2\%) e Primeira 
Cruz (6,9\%). Em 1981, este passou a ser uma Unidade de Conservação (UC) por meio do decreto no 86.060. De acordo com o Instituto Chico Mendes de Conservação da Biodiversidade - ICMBIO (2019), o PNLM compreende uma superfície total de 156.608,16 hectares, com um perímetro de $270 \mathrm{~km}$. Tem cerca de 60 comunidades tradicionais com uma população estimada em mais de 5.000 habitantes. As principais atividades realizadas por estas comunidades são a agricultura, pesca, criação de animais, produção de artesanato, comercialização de castanha de caju e atividades associadas ao turismo. Sua região é composta por areias quartzosas marinhas que desenham uma beleza única de dunas que se movimentam sob a coordenação dos ventos e, devido a possuir um lençol freático bem superficial, origina a formação de lagoas com águas límpidas de cores azuladas e esverdeadas interdunares.

\begin{abstract}
A característica fisiográfica do Parque, devido apresentar uma área de relevo plano, constituído por areias quartzosas marinhas e cordões de imensas dunas de coloração branca, as quais assemelham-se a 'lençóis jogados sobre a cama', originou a denominação da Unidade de Conservação de Lençóis Maranhenses (INSTITUTO BRASILEIRO DO MEIO AMBIENTE E DOS RECURSOS NATURAIS RENOVÁVEIS, 2002, p. 5)
\end{abstract}

Este cenário é revelado ao mundo no ano de 2000, após a inauguração da estrada MA-402, depois transformada em BR-402, que vai do município de Bacabeira a Barreirinhas. A estrada transformou a região em Polo Turístico do PNLM. Em 2005, é criado o circuito "Rota das Emoções" que integra as principais atrações turísticas e belezas naturais de três estados do nordeste brasileiro: Ceará, Piauí e Maranhão. Com tudo isso, atualmente, o Parque Nacional dos Lençóis Maranhenses é uma referência, não só para o Maranhão, mas para o mundo: é a "menina dos olhos" do turismo. Por certo tempo, este turismo foi executado de forma não planejada, sem qualquer preocupação ambiental e social do poder público, gerando vários problemas socioambientais. Em 2007, com a criação do ICMBIO, o turismo passou a ser realizado de forma mais regrada com a demanda oportunizando respostas locais.

1 O conceito de Unidades de Conservação está previsto no art. 20, inciso I, da Lei Federal nº 9.985/00: Art. 20. Para os fins previstos nesta Lei, entende-se por: I - unidade de conservação: espaço territorial e seus recursos ambientais, incluindo as águas jurisdicionais, com características naturais relevantes, legalmente instituído pelo Poder Público, com objetivos de conservação e limites definidos, sob regime especial de administração, ao qual se aplicam garantias adequadas de proteção. 
Entretanto, é interessante ressaltar que o Parque não é constituído somente por sua beleza exuberante, não são só dunas e lagoas como as mídias mostram este paraíso ao mundo. Muito antes mesmo de o Parque se tornar uma UC, já havia pessoas que moravam ali há muito tempo. Filho et al. (2019, p. 50) fala que "a histórica ocupação dessas localidades, antes mesmo da criação do PNLM em 1981, possibilitou a constituição de formas específicas de relação com o meio biofísico..." As famílias que moram no entorno do Parque interagem com diferentes formas de vida que fazem parte da UC, reproduzindo o seu próprio modo de vida. Diante disso, em qualquer inciativa que implique o Parque Nacional dos Lençóis Maranhense devem ser levadas em consideração as comunidades tradicionais que vivem neste território. Uma Unidade de Conservação tem como missão a proteção integral, isso inclui tanto a proteção à biodiversidade identificada nos diferentes ambientes do PNLM, como também ao modo de vida das populações tradicionais ali existentes.

O Projeto de Lei do Senado $n^{\circ} 465$, de 2018 tem como proposta alterar os limites do Parque Nacional dos Lençóis Maranhenses, ampliando e excluindo áreas para promover o desenvolvimento do turismo na região e fazer justiça com as comunidades que precisam de equipamentos públicos básicos. Entretanto, o autor deste projeto, o Senador Roberto Rocha, quando fala em desenvolvimento do turismo tem a pretensão de trazer para o Parque grandes empreendimentos como cassinos e resorts, falando em gerar desenvolvimento sustentável e econômico, em melhorar o turismo para receber os visitantes. O trecho em que se preocupa com os moradores é quando diz que precisa excluir as comunidades da Área de Proteção Ambiental do Parque, porque estas precisam de escolas e serviços públicos e não podem ter porque estão dentro desta área de proteção ambiental. Não é claro quanto ao seu real objetivo, deixando margem para várias questões. Segundo nota técnica publicada pelo GERUR (2019) e pelo ICMBio (2019), a retirada dessas comunidades do perímetro do Parque provocará o aumento de sua vulnerabilidade, devido à forte pressão imobiliária no local.

Diante disso, este artigo é um estudo que objetiva compreender como as comunidades de Santo Amaro, que representam 42,02\% do Parque Nacional dos Lençóis Maranhenses, veem este PLS 465/2018. Será que elas estão sendo ouvidas? Será que elas estão entendendo o objetivo do PLS? Será que elas são a favor ou contra? Qual a verdadeira percepção destas comunidades frente a esta questão? Afinal, estas fazem parte das vidas que serão afetadas, a importância de ouvi-las parece ser persistente. 
Para a realização desta pesquisa foi necessário fazer um levantamento bibliográfico e de relatórios técnicos, analisar audiências públicas e aplicar entrevistas semiestruturadas de forma individual e em grupos focais com as comunidades do Parque. Foram escolhidas as comunidades de Santo Amaro, devido à relação que os autores desta pesquisa têm com o município, já que estão elaborando a dissertação do mestrado e trabalhando em um projeto de implantação de turismo de base comunitária nesta região.

Até o momento foram realizadas entrevistas somente com algumas comunidades de Santo Amaro, de julho a dezembro de 2019, uma vez que esta pesquisa ainda se encontra em andamento. Ao todo foram feitas 28 (vinte e oito) entrevistas individuais e um grupo focal com 39 pessoas. Dos 28 (vinte e oito) entrevistados, 15 (quinze) são da sede do município (moradores, secretaria de turismo, agências de turismo, restaurantes, cooperativa de turismo e prestadores de serviços de quadriciclos para passeios turísticos). Os outros 13 (treze) entrevistados são famílias das comunidades de Santo Amaro que ficam no entorno do PNLM (Espigão, Buriti Grosso, Morro de Espia, Dunas do Lavado do Maneco, Serra da Rancharia e Queimada Grande). O grupo focal foi realizado com moradores do povoado Buritizal.

Na segunda parte deste artigo, serão abordadas informações sobre o Projeto de Lei do Senado 465/2018 e a Análise Técnica do Projeto. Logo em seguida será apresentado o olhar das comunidades de Santo Amaro sobre o PSL 465/2018. E por fim, as considerações.

\section{Projeto de Lei do Senado 465/2018 e análise técnica do projeto}

Os grandes discursos desenvolvimentistas costumam prometer às comunidades impactadas, crescimento, geração de renda e melhor qualidade de vida: são intitulados de desenvolvimento sustentável. De acordo com Stefanuto et al. (2015, p.58), "desenvolvimento sustentável pode ser definido como um processo de transformações estruturais ao longo do tempo, cujos resultados são positivos e podem ser verificados na esfera econômica, ambiental e, sobretudo, em toda a sociedade". No entanto, observa-se, ao longo do tempo, que muitas dessas promessas são efetivadas apenas para uma minoria privilegiada. Quais grupos específicos têm sido beneficiados por esses discursos desenvolvimentistas? A disparidade de poder entre os atores envolvidos proporciona desconfiança e dificuldade de diálogo. 
O Projeto de Lei do Senado 465/2018 tem como autor o Senador Roberto Rocha. Na audiência realizada no Senado, no dia 22 de maio de 2019, informou que o projeto foi idealizado quando foi visitar Betânia, uma comunidade que está em uma das rotas turísticas oficiais de Santo Amaro. Conversando com as pessoas do local, ele descobriu que lá havia uma precária escola para as crianças e nenhum posto de saúde. Sensibilizado, foi até a prefeita de Santo Amaro e descobriu que o desenvolvimento econômico era extremamente limitado, devido às regras previstas na legislação que regula a ocupação das áreas que fazem parte do Parque. Diante disso, elaborou o PLS 465/2018 (AGÊNCIA SENADO, 2019), que visa excluir das áreas protegidas comunidades que foram indevidamente incluídas no interior da unidade e que estão sendo privadas do acesso a equipamentos públicos imprescindíveis.

O Projeto está estruturado em 13 páginas, constituídas por 1 capa, 9 páginas com 5 artigos, sendo 8 páginas com 330 coordenadas planas aproximadas, 2 páginas de justificativa (9 parágrafos) e 1 página com duas legislações citadas.

$\mathrm{Na}$ justificativa, alega-se a importância do turismo na região, dizendo que é o principal destino turístico do estado e um dos principais do país, e que está inserido na Rota das Emoções, atraindo turistas do mundo inteiro. Também é relatado que o Parque Nacional dos Lençóis Maranhenses foi criado em 1981 e que, nessa época, quase não havia ferramentas precisas de geoprocessamento disponíveis, elaborando, assim, um memorial descritivo simplório. Nesse sentido, isso gerou um grande problema às comunidades que foram incluídas no Parque, cujas regras de utilização do espaço físico são extremamente restritivas, acarretando vários problemas graves. Essas regras proíbem a construção de equipamentos públicos como escolas e unidades de saúde, restaurantes, pousadas e hotéis, num território onde a vocação econômica é justamente o turismo. Em se tratando do turismo, o autor relata que:

\begin{abstract}
Sabemos que o turismo sustentável é um grande aliado da conservação, especialmente no entorno de parques nacionais, categoria de unidade de conservação que tem entre os seus principais objetivos a visitação pública. Restrições ao desenvolvimento de atividades econômicas harmônicas com a preservação ambiental resultam em degradação na medida em que impedem a geração de renda, levando a população a buscar formas predatórias de sobrevivência (PLS 465, 2018, pág. 11).
\end{abstract}

Diante disso, finaliza justificando que seja redefinida a delimitação do Parque apresentando um novo memorial que reduzirá para cerca de 660 o número de pessoas no interior da unidade de conservação e ainda ampliará a área protegida em aproximadamente 
4.80o hectares, em áreas onde não há ocupação humana e que tem uma relevância natural. O Parque passaria de $156.608,16$ hectares para 161.409 hectares com o novo formato. $O$ senador Roberto Rocha fala que:

O objetivo deste projeto é promover o turismo sustentável na região, a exemplo do que ocorre no Parque Nacional de Jericoacoara, no Ceará, onde o processo de criação daquela unidade de conservação deixou a Vila de Jericoacoara fora da área protegida, permitindo assim o desenvolvimento de todo o potencial econômico gerado pela conservação ambiental (PLS 465, 2018, pág. 11).

A análise técnica deste PLS foi solicitada pela Federação dos Trabalhadores Rurais Agricultores e Agricultoras do Estado do Maranhão (FETAEMA) e elaborada por uma equipe multidisciplinar de pesquisadores do Grupo de Estudos Rurais e Urbanos (GERUR), da Universidade Federal do Maranhão. O relatório é composto por 62 páginas. Os pontos centrais destacados são que o PLS apresenta muitas limitações técnicas, sobretudo de aspectos jurídicos, geográficos, sociais e ambientais e maior valorização das possibilidades de negócios do turismo que propriamente uma preocupação ambiental e social. São apresentados vários mapas, entre eles, um que mostra o limite atual do PNLM e o limite proposto pelo PLS 465/2018, exibido logo a seguir:

Figura 1 - Limite atual e limite proposto PLS 465/2018 - Parque Nacional dos Lençóis Maranhenses

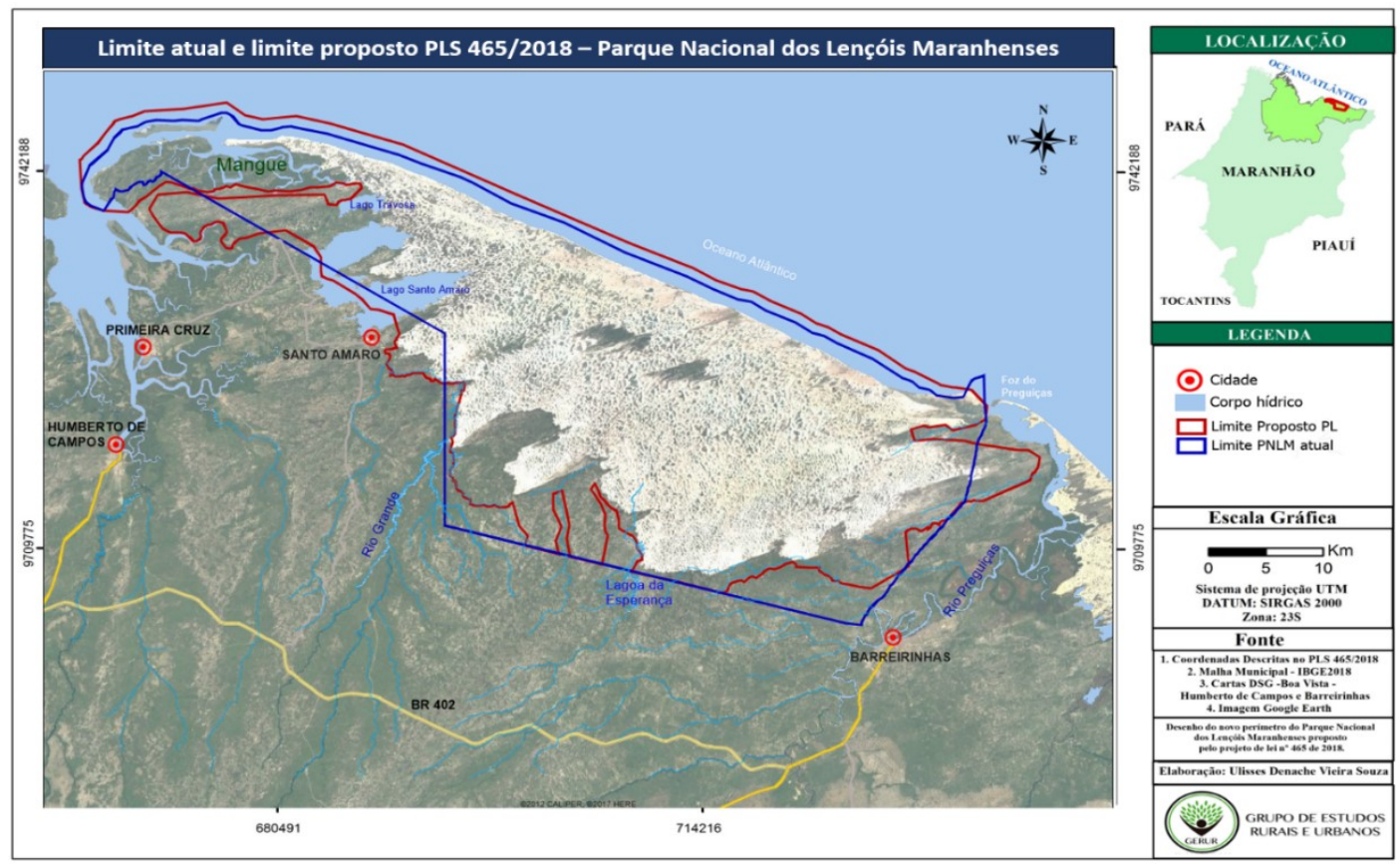

Fonte: Nota Técnica n³ 3/2019/PARNA Lençóis Maranhenses/ICMBio 
De acordo com o relatório, este mapa nos revela o que esse novo perímetro apresenta: ampliação de 5 áreas (17.351,73ha) e exclusão de 9 áreas (12.897,8oha). Pelos números, parece uma boa conta matemática, mas, na prática, não é isso que demonstra. As 5 áreas ampliadas são para o oceano. E as 9 áreas excluídas são no entorno do Parque, onde vivem as comunidades. É ressaltado no relatório que, quando o senador Roberto Rocha critica a forma como foi desenhado o memorial para a criação do Parque, em 1981, ele repete os mesmos erros criticados para a elaboração do PLS 465/2018.

O termo 'coordenadas planas aproximadas' (c.p.a), citado na página 01 do PLS, significa que os 330 pontos indicados no memorial descritivo, que delimitam o novo perímetro proposto para o PNLM, não foram obtidos a partir de um processo de georreferenciamento preciso (INFORMAÇÃO TÉCNICA DO PLS 465/2018, 2019, p.6).

E chama a atenção para dois aspectos: a proteção do meio ambiente e a garantia dos direitos das populações tradicionais, ambas encontram respaldo na Constituição Federal e em dispositivos jurídicos nacionais e internacionais, como o Sistema Nacional de Unidades de Conservação (SNUC), o Decreto n 6.040 e a Convenção 169/OIT. A equipe da análise técnica sugere uma alternativa: "seria a de se pensar, no próprio PLS, em limites específicos, tanto para proteger a biodiversidade no interior do PNLM, quanto para amparar as populações tradicionais e o seu modo de vida de forma sustentável".

Quando o senador fala que as famílias foram indevidamente inclusas nas áreas de proteção do Parque, no momento que este foi criado, prejudicando-as, por outro lado, ele também não menciona durante todo o projeto qualquer medida para proteger essas famílias. No relatório, faz-se uma menção a respeito disso:

\footnotetext{
Não figura no PLS qualquer iniciativa no sentido de proteger o modo de vida das comunidades tradicionais que historicamente vivem e trabalham no PNLM. Ao contrário, excluindo-as dos seus limites, simplesmente propõe jogá-las em uma situação de vulnerabilidade, de assédio de parte de especuladores imobiliários, transformando-as ainda em mão de obra desqualificada e barata num médio prazo. Deste modo, de acordo com o PLS, lucrarão apenas os que desejam adquirir terras nessas áreas excluídas da unidade de conservação para ali implantarem seus negócios voltados ao turismo (INFORMAÇÃO TÉCNICA DO PLS 465/2018, 2019, p.10).
}

Em se tratando da parte em que se fala, no PLS, sobre o "turismo sustentável" no PNLM, em nenhum momento se questiona a organização do turismo já existente na região. Muito menos mostra preocupação com o modo de vida das pessoas no Parque, uma vez que o turismo sustentável é comprometido com as questões socioambientais do local. Sobre isso, o relatório técnico chama a atenção quando diz: 
O que está em jogo, subjacente à proposta do PLS, é a transformação da natureza em mercadoria altamente rentável no mercado do turismo. Nesse caso, as belezas cênicas do PNLM - como as de outros Parques Nacionais brasileiros - contribuiriam para uma commoditização da natureza² (INFORMAÇÃO TÉCNICA DO PLS 465/2018, 2019, p.11).

E, quando o PLS menciona o Parque Nacional de Jericoacoara como exemplo para o PNLM, no que tange à promoção do desenvolvimento turístico sustentável, que, no ato da criação da UC deste Parque deixou a Vila de Jericoacoara fora da área de proteção, parece privilegiar o interesse empresarial. Ele fala do desenvolvimento econômico, mas omite os malefícios causados às comunidades tradicionais de Jericoacoara. Segundo o relatório:

[...] A exclusão se deu justamente em um contexto de fortalecimento do turismo, desconhecendo-se os efeitos para o modo de vida das comunidades tradicionais historicamente enraizadas naquela região. Pergunta-se: a qualidade de vida das famílias daquela antiga Vila de pescadores melhorou após a exclusão dessa porção do perímetro daquele Parque? (INFORMAÇÃO TÉCNICA DO PLS 465/2018, 2019, p.12)

Diante dessas questões, o relatório nos mostra os principais problemas da exclusão das áreas que são a criação de uma situação de insegurança ambiental e social, liberação de terras públicas para disponibilização no mercado de terras e estímulo à especulação imobiliária.

Os principais problemas ambientais da exclusão das áreas seriam a supressão de áreas de Restinga, como mostra a tabela a seguir:

\begin{tabular}{c|c|c|c|c}
\hline \multirow{2}{*}{$\begin{array}{c}\text { Unidades de } \\
\text { paisagem }\end{array}$} & $\begin{array}{c}\text { Decreto } \\
\mathbf{8 6 . 0 6 0 / 1 9 8 1}\end{array}$ & \multicolumn{2}{c|}{ PLS 465/2018 } & \multicolumn{2}{c}{ Diferença } \\
\cline { 2 - 5 } & \multicolumn{2}{|c|}{ Área } & Ha & $\%$ \\
\hline Dunas & 98.121 & 99.335 & 1.214 & 1,23 \\
\hline Oceano & 10.425 & 20.032 & 9.607 & 92,15 \\
\hline Lago & 5.601 & 6.313 & 712 & 12,71 \\
\hline Restinga & 29.908 & 22.307 & -7.601 & $-25,41$ \\
\hline Mangue & 13.920 & 16.021 & 2.101 & 15,09 \\
\hline Total & $\mathbf{1 5 7 . 9 7 5}$ & $\mathbf{1 6 4 . 0 0 8}$ & $\mathbf{6 . 0 3 3}$ & $\mathbf{3 , 8 1}$ \\
\hline
\end{tabular}

Fonte: Nota Técnica nº 3/2019/PARNA Lençóis Maranhenses/ICMBio

\footnotetext{
${ }^{2}$ A economista Amyra El Khalili define a comoditização da natureza como o processo que transforma um bem comum em mercadoria (TROCATE, ZANON, VIEIRA, 2015, p. 41)
} 


\section{O olhar das comunidades de Santo Amaro sobre o PLS 465/2018}

O município de Santo Amaro do Maranhão abrange a área ocidental dos Lençóis Maranhenses, equivalente a 42,2\% do Parque Nacional dos Lençóis Maranhenses. Tem sua expansão por $1.601,2 \mathrm{~km} 2$ e, de acordo com o último censo, havia 13.820 habitantes. Sua população previsivel para 2018 foi de 15.654 (IBGE). Santo Amaro do Maranhão tem seu limite ao Norte com o Oceano Atlântico; a Leste com o município de Barreirinhas; a Oeste com o município de Primeira Cruz e ao Sul com o município de Barreirinhas. Suas principais atividades produtivas estão representadas pela agricultura, pecuária, pesca, o extrativismo vegetal e o turismo. As lagoas têm duração efêmera, são atrativas quando estão cheias durante os meses de verão e outono e quase inexistentes durante a estação seca, que corresponde ao inverno e à primavera.

O turismo em Santo Amaro teve sua promoção alicerçada no discurso de desenvolvimento econômico, geração de emprego e renda, de preservação ambiental, de melhoria e qualidade de vida, desenvolvimento regional e da infraestrutura.

[...] considerar a atividade turística como sustentável ou como integrante da possibilidade do desenvolvimento sustentável é apenas desviar os termos da questão sem analisar a complexidade de uma atividade econômica que tem por base o consumo de paisagens naturais exóticas ou a história passada (RODRIGUES, 2000, p.174).

Ruschmann (1997, apud FERREIRA, 2005, p.19) também contribui afirmando que "o turismo pode causar diferentes impactos, tais como econômicos, sociais, culturais e sobre o meio ambiente natural e que eles podem dar-se de forma positiva ou negativa, ou seja, podem trazer benefícios e prejuízos".

Os moradores de Santo Amaro não estão desatentos às potencialidades turísticas da localidade, sendo relevantes as suas participações nesse processo.

Em 2018, no mês de junho, o turismo em Santo Amaro adquire uma nova dinamização com a inauguração da rodovia MA 320 que tem seu destino final nas proximidades da sede do município, saindo da BR 402 até a altura do povoado Pedras, consagrando outra importante entrada ao Parque Nacional dos Lençóis Maranhenses. O fluxo da demanda turística, desse período em diante, exibe um considerável acréscimo nos feriados e fins de semana no município.

Para a execução do projeto, em 2019, foram realizadas entrevistas em algumas comunidades de Santo Amaro, tanto na sede (nos dias 12, 13, 14 e 15 de julho), como no 
entorno do PNLM (Espigão, Buriti Grosso, Morro de Espia, Dunas do Lavado do Maneco, Serra da Rancharia) nos dias 8, 9 e 10 de agosto e Queimada Grande no dia 13 de dezembro. Ao todo, foram aplicadas 28 entrevistas individuais e um grupo focal com 39 pessoas em Buritizal nos dias 4 e 5 de outubro.

Na sede de Santo Amaro foram realizadas 15 entrevistas, sendo a primeira com o secretário municipal de turismo da Santo Amaro. O secretário revela uma séria preocupação sobre a PLS. Acredita que, com a exclusão das comunidades que estão no entorno do Parque da área de proteção ambiental, vai haver uma grande especulação imobiliária atraindo megaempreendimentos turísticos que poderão levar à exclusão dos moradores locais da dinâmica do turismo e de seu próprio habitat, além da degradação ambiental avassaladora. Ele ressalta que, atualmente, a população de Santo Amaro é bem envolvida com as atividades do turismo, que querem o turismo como fonte de renda. Relata que muitas famílias das comunidades do entorno do Parque se tornaram empreendedoras, naturalmente, para trabalhar com turismo sem precisarem de capacitação adaptando ao seu próprio modo de viver. A grande preocupação, caso seja aprovada o PLS, é o que vai acontecer com estas comunidades? Também diz que não foi procurado pelo autor do PLS para alguma contribuição na elaboração deste projeto, nem apenas para saber se era do desejo das comunidades.

Ainda na sede, foram feitas entrevistas com cinco agências de turismo receptivo 3 , uma cooperativa de transporte turístico, dois restaurantes, três prestadores de serviços de quadriciclos para passeios turísticos e três moradores da sede. Os donos das agências e o presidente da cooperativa de transporte turístico foram unânimes em dizer que não eram a favor do PLS e que souberam do projeto através de colegas de profissão do município de Barreirinhas. Eles acreditam que, abrindo o mercado turístico para empresários de fora de Santo Amaro, irão perder seu espaço dentro da atividade turística local. Os prestadores de serviços para passeios em quadriciclos e os três moradores não tinham conhecimento sobre o PLS e não souberam opinar se era bom ou ruim para eles. No entanto, vale destacar a fala de um dos moradores, o tio Juca, um simpático senhor de 94 anos, com muita lucidez:

3 As agências de turismo receptivo assessoram o turista enquanto estiver no destino da viagem; e elaboram e vendem ao turista passeios e programas locais, cobrados à parte do pacote turístico. (TOMELIN, 2001, p. 24) 
[...] o turismo melhorou muito a vida das pessoas daqui, aqui não era nada antes, a gente tinha carne pra vender e não tinha pra quem vender, ninguém chegava aqui... quando aparecia alguém era anunciado na praça pra matar o boi e fazer a venda, todo mundo corria pra praça...Hoje nossos fios já não vão mais embora como antes pra ser alguém na vida e ficam pra trabalhar com o turismo aqui, o turismo deu dignidade pra gente...

É interessante esse depoimento porque leva a uma reflexão de como essas pessoas tão simples conseguiram se organizar na dinâmica do turismo. Como pensar em outro modelo de turismo, sem levar em consideração esse diálogo?

Das treze entrevistas ocorridas com as comunidades no entorno do Parque, duas destas famílias (uma em Buriti Grosso e outra em Lavado do Maneco) não quiseram responder à entrevista, acreditando que nossa equipe era de algum órgão que fosse tirá-las de sua casa. Mesmo explicando que era apenas uma pesquisa para um trabalho acadêmico, mostraram-se desconfiadas e permaneceram resistentes. Observou-se, então, uma certa apreensão por algo de que mal entendiam e que ainda está em trâmite. Algumas famílias aceitaram dar entrevistas, desde que não assinassem nada. Todas disseram, até aquele momento, nunca terem sido informadas ou participarem de alguma reunião que discutisse o PLS. Aproximadamente $70 \%$ das famílias entrevistadas desconheciam o PLS. As que tinham algum conhecimento se mostraram contra o PLS. Foram quase unânimes quando falaram que gostam ou gostariam de trabalhar com o turismo sem alterar muito seu modo de viver, apenas uma família (Serra da Rancharia) não mostrou interesse. As que trabalham com o turismo falaram que os mais novos estão permanecendo nas suas comunidades para ajudar na renda. Até as famílias que não sabem sobre o PLS sabem, de alguma forma, que talvez tenham que sair das suas casas. Mesmo sem entenderem, se sentem ameaçadas, mostram sentimento de temor.

Em outubro, a autora desta pesquisa ministrou um curso sobre turismo de base comunitária ${ }^{4}$, de um dia e meio na comunidade de Buritizal, onde houve a presença de 39 moradores (entre eles moradores de povoados vizinhos como Tucuns, Serra da Rancharia e

\footnotetext{
4 O turismo comunitário é realizado de forma integrada às demais atividades econômicas, com iniciativas que fortalecem a agricultura, a pesca e o artesanato, dentre outras atividades. Prioriza a geração de trabalho para os residentes nas comunidades, os pequenos empreendimentos locais, a dinamização do capital local, a garantia da participação de todos, dando espaço também às mulheres e aos jovens. Assegura a participação das pessoas das comunidades com o planejamento descentralizado e associativo, luta pela regulamentação fundiária e pela garantia da posse da terra de populações indígenas, pesqueiras, as chamadas comunidades nativas. (CORIOLANO, 2006, p.202).
} 
Lavado do Maneco). Na ocasião, aplicou-se a entrevista com toda a turma (grupo focal). Estes alunos disseram ter ciência do PLS e que souberam através de amigos que trabalham com transporte de turismo na sede e que não acham uma boa ideia para eles. Relataram que, até aquela data, ninguém ainda havia falado com eles sobre esse assunto. Um aluno disse não entender o motivo deste projeto feito por uma pessoa que não mora lá e sem ser solicitado por ninguém que mora no Parque. Todos eles falaram que sentem receio de vir gente montar empresa de fora em sua região e expulsarem eles de lá. Vale ressaltar que Buritizal ainda não está dentro de uma rota oficialmente turística, mas é uma comunidade que deseja ser inserida neste mercado e que, se isso vier a ocorrer, tem intenção investir nesse ramo.

Em Queimada Grande, foram entrevistadas duas famílias no dia 13 de dezembro. Uma delas nunca ouvira falar deste PLS. Já a outra, representada por uma menina de 16 anos, conhecida por Santinha, mostrou saber muito a respeito. Disse ter participado de duas reuniões com o ICMBio. Na sua perspectiva, relata não ser a favor do PLS,

[...] não seria bom não...se eles tirar as comunidades do Parque e liberar para empreendimentos, aí a renda vai ser mais pra eles do que pra gente? Eles iam tipo, englobar a gente, aí a gente ia ser empregados deles, não ia ter como a gente fazer aquela nossa renda, eles vão crescer mais do que a gente, em vez da gente crescer, eles vão crescer mais ainda...e ainda iam destruir o Parque que tanto a gente preserva...

Em suas falas, essa moça demonstra que não quer sair do Parque, que gostaria de fazer sua renda sem ser explorada por empresas e que defende a proteção ambiental do Parque, ela demonstra a sua relação de vida com o Parque e o que deseja para o futuro dela.

Nota-se que, das primeiras entrevistas aplicadas até a entrevista do grupo focal, as pessoas vão, aos poucos, tomando conhecimento sobre o PLS e formando suas opiniões e entendimentos sobre o assunto.

Entretanto, na audiência pública ocorrida no dia 1 de novembro de 2019 em Santo Amaro do Maranhão, na primeira tentativa de diálogo com as comunidades do Parque sobre essa questão, foi manifestado o tamanho da rejeição popular. Eram aproximadamente 300 pessoas representando os três municípios do PNLM (Barreirinhas, Santo Amaro e Primeira Cruz). A princípio, a audiência seria na Casa do Artesanato e, pela quantidade pessoas presentes (que não era esperado), teve que ser transferida para o Clube do Mota, local que poderia acomodar este número de pessoas. Além dos moradores, estavam presentes ambientalistas, representantes de movimentos sociais e pesquisadores. O senador Roberto Rocha foi recebido com vaias, cartazes e palavras que traduziam repúdio ao projeto como 'O 
Parque é nosso, não queremos que transforme negócio' (Fonte: http://edwilsonaraujo.com/quem-somos/).

Diante disso, a população demonstra saber o que quer e entender, após o discurso do senador, que o projeto quer beneficiar a especulação imobiliária e que não está preocupado com os impactos na vida das pessoas que vivem historicamente nessa região. A revolta foi maior quando o senador chegou e disse: "Desci do helicóptero num lugar tão bonito que deu vontade de comprar um terreno, além do que eu já tenho". (Fonte: http://edwilsonaraujo.com/quem-somos/).

Após essa audiência, ficou perceptível que não são somente os pesquisadores e estudiosos que temem a concretização deste PLS, mas as comunidades compreendem e temem, também, que a explosão imobiliária os deixe de fora de seu habitat e que sejam afetados por todos os possíveis impactos socioambientais nocivos à biodiversidade do PNLM.

Diante desse repúdio popular, agora será aguardar que rumo essa história irá tomar e observar se as vozes das comunidades serão escutadas nesse processo do PSL 465/2018.

\section{Considerações finais}

A discussão deste artigo traz percepções dos diversos atores envolvidos no PLS 465/2018, criando uma oportunidade de avaliar e refletir sobre questões que promovem atuações estratégicas quando se fala em desenvolvimento. Um projeto que visa modificar a vida das pessoas tem que se fazer necessário um diálogo com elas. São famílias que vivem historicamente nesta região, que tem uma relação de interação com a biodiversidade do Parque, o que faz delas protetoras deste ambiente, conservadoras da natureza. É necessário estar em harmonia com os direitos humanos para que se possa promover ações de desenvolvimento local onde se instalam os empreendimentos. É preciso entender como vivem as pessoas na área do PNLM, do que elas vivem, como elas trabalham, qual o papel delas com os seres não humanos que compreendem o Parque. Como explicou o antropólogo Benedito Souza, em uma audiência feita no senado pela Comissão de Meio Ambiente Desenvolvimento Sustentável, no dia 6 de dezembro de 2019, "Qualquer projeto que modifique o modo de vida das pessoas tem que tratar estas como principais interlocutoras". 
Poucas iniciativas atuam nessa linha de pensamento. É preciso haver uma mudança de mentalidade em função da absorção de práticas sustentáveis. Em outras palavras, colocar em prática ações alicerçadas em perspectivas e solidificação de valores que prezem pelo respeito a patrimônios sociais, culturais e ambientais. A economista Rachel Stefanuto (2015, p.63) diz que, para isso, é essencial requerer:

[...] um trabalho estratégico de parcerias que demanda diálogo e atuação consciente do governo, da iniciativa privada, além de intensa e sistemática participação da sociedade civil, todos com as mesmas condições de participação ativa nos processos e ações para o planejamento do desenvolvimento sustentável.

\section{Agradecimentos}

Ao Núcleo de Extensão e Desenvolvimento - LABEX e ao mestrado do Programa de Pós-Graduação em Desenvolvimento Socioespacial e Regional - PPDSR, ambos da Universidade Estadual do Maranhão - UEMA. Ao Consórcio Público Intermunicipal das Mesorregiões Norte e Leste Maranhense - CONLESTE. À Prefeitura Municipal de Santo Amaro do Maranhão. E ao Colegiado de Desenvolvimento Territorial Lençóis Maranhenses Munim CODETER. Todos tiveram uma grande contribuição para a realização deste artigo.

\section{Referências}

ANDRADE, M.P.; FILHO, B.S. et al. Análise Técnica do Projeto de Lei do Senado (PLS) que altera os limites do Parque Nacional dos Lençóis Maranhenses. Senado Federal. 2019. Disponível em: <https://legis.senado.leg.br/sdleggetter/documento?dm=7959672\&ts=1559164632310\&disposition=inline $>$. Acesso em: 30 novembro de 2019 .

ARAÚJO, Ed Wilson Ferreira. Quem somos. Ed Wilson Araújo, [s.l.], 2019. Disponível em: dwilsonaraujo.com/quem-somos/. Acesso em 30 novembro de 2019.

CORIOLANO, L. N. M. T. O Turismo nos Discursos, nas Políticas e no Combate à Pobreza. São Paulo: Annablume, 2006

DENCKER, A. F. M. Métodos e técnicas de pesquisa em turismo. 3. ed. São Paulo: Futura, 2000.

FERES, R. Lençóis maranhenses. 2017. Disponível em: http://ricardoferes.com/project/lencois-maranhenses/. Acesso em: 30 novembro de 2019. 
FERREIRA, Sidney G. Os impactos do turismo nas pequenas cidades: um estudo em Itapecerica - MG. Dissertação (Mestre em Administração área de concentração em "Gestão Social e Meio Ambiente e Desenvolvimento) - Universidade Federal de Lavras, MG, 2005.

FILHO, Benedito S. Comunidades tradicionais e formas de interação com a natureza: a relação entre humanos e não humanos no Parque Nacional dos Lençóis Maranhenses. In. NETO, Joaquim S. [et. al] (orgs.). Problema ambiental: natureza e sujeitos em conflito. São Luís: EDUFMA, 2019.

IBGE. Panorama: população. [S.I], 2020. Disponível em: https://cidades.ibge.gov.br/brasil. Acesso em: jul. 2020.

ICMBIO. Parna dos Lençois Maranhenses. Disponível em: http://www.icmbio.gov.br/portal/unidadesdeconservacao/biomasbrasileiros/marinho/unidades-de-conservacao-marinho/2264-parna-dos-lencoismaranhenses. Acesso em: 30 nov. 2019.

INSTITUTO BRASILEIRO DO MEIO AMBIENTE E DOS RECURSOS NATURAIS RENOVÁVEIS (IBAMA). Plano de Manejo do Parque Nacional dos Lençóis Maranhenses. Brasília: IBAMA/ UFMA, 2002.

INSTITUTO CHICO MENDES DE CONSERVAÇÃO DA BIODIVERSIDADE. Parque Nacional dos Lençóis Maranhenses. Disponível em:

http://www.icmbio.gov.br/parnalencoismaranhenses/guia-do-visitante.html. Acesso em: 30 novembro de 2019 .

LOBATO, F. M. Descentralização de políticas públicas de turismo: a municipalização do turismo no Maranhão. 2001. 236 f. Dissertação (Mestrado em Ciências da Comunicação) Departamento de Relações Públicas, Propaganda e Turismo, Universidade de São Paulo, São Paulo, 2001.

Projeto de lei do Senado $n^{\circ}$ 465, de 2018. Senado Federal. 2018. Disponível em: $<$ https://legis.senado.leg.br/sdleggetter/documento?dm=7891159\&ts=1594018168095\&disposition=inline $>$. Acesso em: 30 novembro de 2019 .

RIBEIRO, E. Governadores do Ceará, Piauí e Maranhão selam consórcio para desenvolvimento integrado do turismo. 2008. Disponível em: http://www.psbceara.org.br/imprime.asp?id=181\&var=IMPRENSA\%20PSB\&c=. Acesso em 30 novembro de 2019.

RODRIGUES, A. B. Turismo e Espaço. Rumo a um conhecimento transdisciplinar. São Paulo: Editora HUCITEC, (1997) 
RODRIGUES, Arlete M. Desenvolvimento sustentável e atividade turística. In: SERRANO, Célia; BRUHNS, Heloisa T.; LUCHIARI, Maria Tereza D. P. (Org.). Olhares contemporâneos sobre o turismo. Campinas: Papirus, 2000. p. 171-188.

RUSCHMANN, Doris Van de Meene. Turismo e planejamento sustentável: a proteção do meio ambiente. Papirus Editora, 1997.

SANTOS, R. Senador do Maranhão discute estratégias para a Rota das Emoções. Disponível em: http://blogdoricardosantos.com.br/2017/06/23/senador-do-maranhaodiscute-estrategias-para-a-rota-das-emocoes/. Acesso em 30 novembro de 2019.

SILVEIRA, M. A. T. Turismo, políticas de ordenamento territorial e desenvolvimento: um foco no estado do Paraná no contexto regional. 2002. 240 f. Tese (Doutorado em Geografia) - Faculdade de Filosofia, Letras e Ciências Humanas, Universidade de São Paulo, São Paulo, 2002.

STEFANUTO, Rachel C. Desenvolvimento Sustentável e Comunidades. In. FLOREZ, Margareth: [et. al]. Olhares sobre desenvolvimento comunitário: 10 perspectivas do impacto gerado por grandes empreendimentos. São Paulo: ILG, 2015.

TOMELIN, Carlos Alberto. Mercado de Agências de Viagens e Turismo: como competir diante de novas tecnologias. São Paulo: Editora Aleph, 2001.

TRENTI, F.; FRATUCCI, A. C. Política Nacional de Turismo no Brasil: da Municipalização à Regionalização. In: INTERNATIONAL CONFERENCE ON TOURISM \& MANAGEMENT STUDIES, 1, Algarve, 2011. Anais Algarve: Book of Prodeedings, 2011. p.1-10.

TROCATE, Charles; ZANON, Maria Julia; VIEIRA, Jarbas (org). Elementos Constitutivos do MAM (Movimento pela Soberania Popular na Mineração). Marabá, Ed. Iguana, 2015.

\section{Detalhes dos autores}

Itaan de Jesus Pastor Santos

Professor e orientador. Universidade Estadual do Maranhão Doutor em Agronomia pela Universidade Técnica de Lisboa. E-mail: itaanps@gmail.com

\section{Michelle Santos Rocha}

Turismóloga e mestranda em Desenvolvimento Socioespacial e Regional da Universidade Estadual do Maranhão. E-mail: mimi.slz@hotmail.com 